\title{
The role of particle ripening on the creep acceleration of Nimonic 263 superalloy
}

\author{
Giuliano Angella, Riccardo Donnini, Dario Ripamonti ${ }^{a}$, and Maurizio Maldini \\ IENI-CNR, via Roberto Cozzi, 53, 20125 Milano, Italy
}

\begin{abstract}
Physically based constitutive equations need to incorporate the most relevant microstructural features of materials to adequately describe their mechanical behaviour. To accurately model the creep behaviour of precipitation hardened alloys, the value and the evolution of strengthening particle size are important parameters to be taken into account. In the present work, creep tests have been run on virgin and overaged (up to $3500 \mathrm{~h}$ at $800^{\circ} \mathrm{C}$ ) Nimonic 263 , a polycrystalline nickel base superalloy used for combustion chambers of gas turbines. The experimental results suggest that the reinforcing particle evolution is not the main reason for the creep acceleration that seems to be better described by a strain correlated damage, such as the accumulation of mobile dislocations or the grain boundary cavitation. The coarsened microstructure, obtained by overageing the alloy at high temperature before creep testing, mainly influences the initial stage of the creep, resulting in a higher minimum creep rate and a corresponding reduction of the creep resistance.
\end{abstract}

\section{Introduction}

Nimonic 263 is a wrought Ni-base superalloy extensively used for stationery components of gas turbine. Its creep strength and hot corrosion resistance make it suitable for combustion chambers, bearing housing, liner, casing and so on.

Nimonic 263 is a precipitation hardened alloy, its resistance arising from a fine precipitation of $\gamma^{\prime}-$ $(\mathrm{Ni}, \mathrm{Co})_{3}(\mathrm{Ti}, \mathrm{Al})$ particles.

Its creep behaviour has been widely investigated in the past [1-3]. It is commonly accepted that the occurrence of a minimum creep rate should not be confused with steady state. The shape of the creep curves varies depending on the stress/temperature range and the long accelerating creep stage cannot be accounted for by $\gamma^{\prime}$ coarsening.

Microstructural studies have been performed in the past [4], pointing out that a number of phases other than $\gamma^{\prime}$ are present: $\eta-(\mathrm{Ni}, \mathrm{Co})_{3} \mathrm{Ti}, \mu-(\mathrm{Co}, \mathrm{Ni})_{3} \mathrm{Mo}_{6}, \mathrm{MC}-$ (Ti,Mo)C, $\mathrm{M}_{6} \mathrm{C}-(\mathrm{Co}, \mathrm{Ni})_{3} \mathrm{Mo}_{3} \mathrm{C}, \mathrm{M}_{23} \mathrm{C}_{6}-(\mathrm{Cr}, \mathrm{Mo})_{23} \mathrm{C}_{6}$.

$\gamma^{\prime}$ solvus temperature is about $925^{\circ} \mathrm{C}$ : after prolonged soaking below this temperature, $\eta$-phase starts to precipitate as platelets at the expense of $\gamma^{\prime}$, thus suggesting that $\gamma^{\prime}$ is a metastable phase. Thermodynamic calculation, which states that $\gamma^{\prime}$ is an equilibrium phase only at temperatures lower than $750-900{ }^{\circ} \mathrm{C}$, confirms this assumption [4].

It is reported [5] that ageing influences not only the size of $\gamma^{\prime}$ but also the lattice misfit with $\gamma$, which grows from $0.28 \%$ to $0.50 \%$ after 20000 hours at $700{ }^{\circ} \mathrm{C}$.

\footnotetext{
${ }^{a}$ Corresponding author: dario.ripamonti@ieni.cnr.it
}

In this paper different heat treatment conditions are examined in order to understand how ageing at $800^{\circ} \mathrm{C}$ can influence creep properties and microstructural features.

\section{Materials and experimental}

The nominal chemical composition of Nimonic 263 alloy is (in weight \%) 20.0 Co, 20.0 Cr, 5.8 Mo, 2.1 Ti, 0.7 Fe, $0.6 \mathrm{Mn}, 0.45 \mathrm{Al}, 0.4 \mathrm{Si}, 0.06 \mathrm{C}$.

The heat treatment procedure consists of a 2 hours solution treatment at $1150{ }^{\circ} \mathrm{C}$, followed by water quench and a subsequent 8 hours ageing at $800^{\circ} \mathrm{C}$. The final cooling is provided by still air. In the following, samples in this condition will be referred to as "peak aged".

After this heat treatment the alloy shows equiaxed grains about $100 \mu \mathrm{m}$ large and a fine precipitation pattern of strengthening $\gamma^{\prime}$ particles with a diameter of about $30 \mathrm{~nm}$. The $\gamma^{\prime}$ volume fraction varies with temperature and, according to [1], it decreases from $10 \%$ at room temperature up to $800^{\circ} \mathrm{C}$, to $3 \%$ at $900{ }^{\circ} \mathrm{C}$, before dropping to zero at the solvus temperature $\left(925^{\circ} \mathrm{C}\right)$.

Additional ageing at $800^{\circ} \mathrm{C}$ was carried out in a muffle furnace up to 3500 hours.

Constant load creep tests were run on cylindrical specimens in different ageing conditions. The specimens were machined from $38 \mathrm{~mm}$ diameter bars to obtain four specimens for each section with $5.6 \mathrm{~mm}$ gauge diameter and $28 \mathrm{~mm}$ gauge length. Three $\mathrm{R}$ thermocouples were placed along the gauge length to control temperature and to minimise temperature gradient. Creep elongation was recorded with capacitive transducers connected to extensometers clamped to the specimen shoulders.

This is an Open Access article distributed under the terms of the Creative Commons Attribution License 4.0, which permits unrestricted use, distribution, and reproduction in any medium, provided the original work is properly cited. 


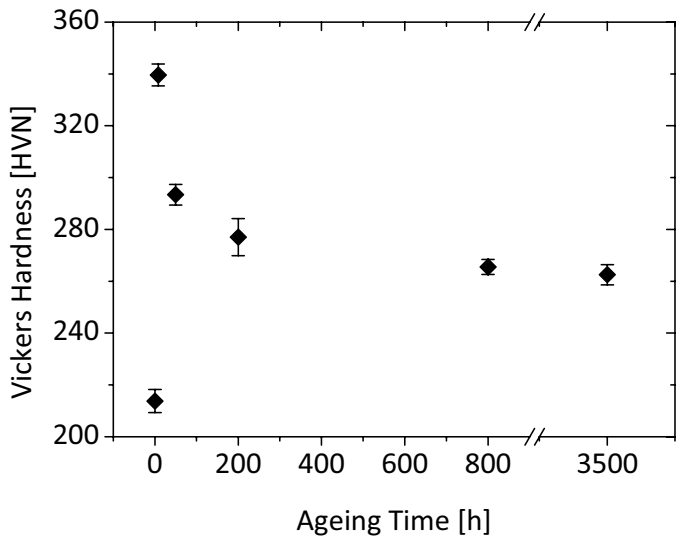

Figure 1. Vickers hardness vs. ageing time at $800^{\circ} \mathrm{C}$ plot.

Results are given in terms of true creep strain, namely

$$
\varepsilon=\ln \left(1+\frac{\Delta l}{l_{o}}\right)
$$

where $l_{o}$ and $\Delta l=l-l_{o}$ are the initial length and the elongation of the specimen gauge during creep, respectively.

Disks (about $10 \mathrm{~mm}$ thick) were cut from the same bars and polished in order to perform Vickers hardness tests, either in solutionised or aged conditions, with an applied load of $60 \mathrm{~kg}(589 \mathrm{~N})$.

Metallographic investigations were performed on aged and on crept samples by means of electron microscopy with a SU-70 microscope by Hitachi, equipped with EDS and STEM detector and provided with a field emission Schottky electron source. The beam can be accelerated up to $30 \mathrm{kV}$. Thin foils for STEM observations were prepared by electro-etching $3 \mathrm{~mm}$ diameter large and 80-100 $\mu \mathrm{m}$ thick discs, obtained via mechanical polishing. The final perforation was performed electrolytically with a double jet system, using a $10 \%$ perchloric acid solution in ethanol, at a temperature of $-15^{\circ} \mathrm{C}$, and an applied voltage of $5-10 \mathrm{~V}$.

\section{Results}

\subsection{Ageing}

The effect of ageing at $800^{\circ} \mathrm{C}$ after solubilisation on the hardness of Nimonic 263 alloy is shown in Fig. 1. A steep increase takes places after 8 hours (peak ageing), followed by a sharp reduction after a few tens of hours. It is worth noting that about one half of the strengthening provided after $8 \mathrm{~h}$ ageing vanishes in about $200 \mathrm{~h}$ and beyond this aging time hardness is roughly constant.

Micrographs of the samples used for hardness measurements are shown in Fig. 2. The size of $\gamma^{\prime}$ particles increases after prolonged ageing at $800{ }^{\circ} \mathrm{C}$.

This phenomenon can be described quantitatively: under the assumptions that particles are randomly distributed, spherical and of the same size, the average particle diameter $d$ can be calculated as [6]

$$
d=\frac{4 N_{L}}{\pi N_{A}}
$$

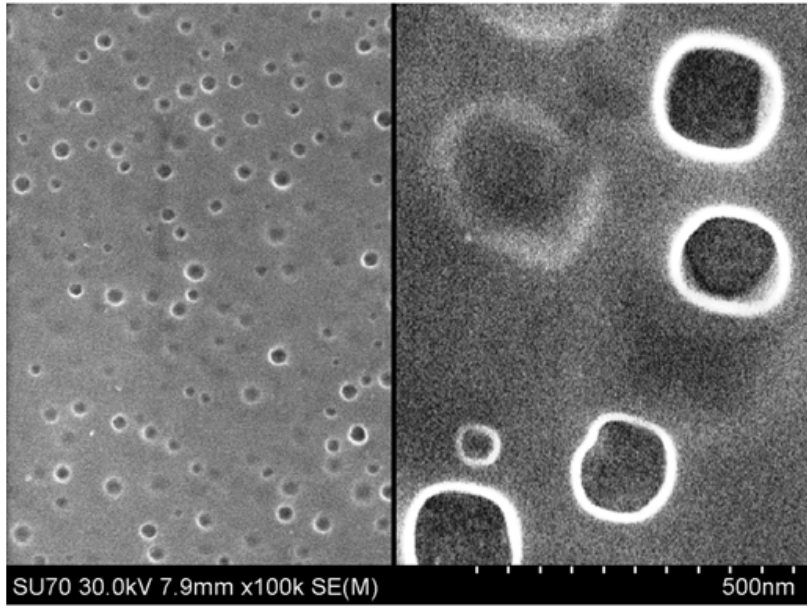

Figure 2. SEM micrographs of samples aged at $800^{\circ} \mathrm{C}$ after $8 \mathrm{~h}$ (left) and after $800 \mathrm{~h}$ (right).

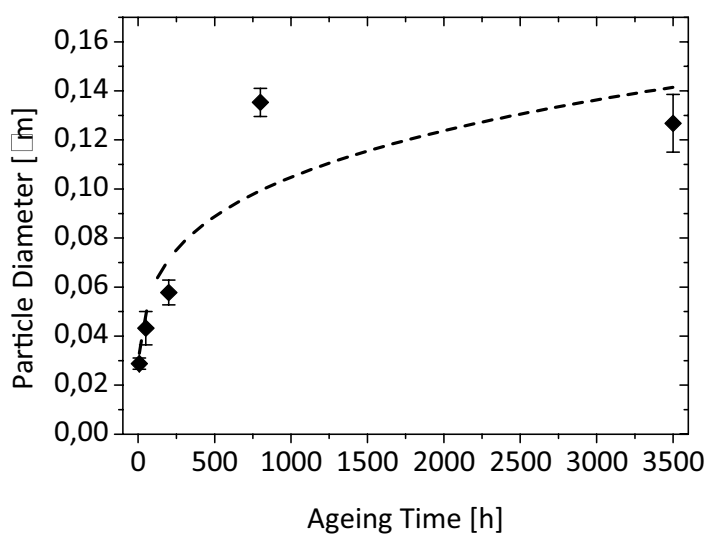

Figure 3. Average $\gamma^{\prime}$ particle diameter d vs. ageing time $t$ at $800^{\circ} \mathrm{C}$ plot. The dashed line represents power law interpolation, with time exponent equal to 0.24 .

where $N_{L}$ represents the number of particles intersected per unit length of a test line and $N_{A}$ is the number of particles per unit test area. A plot $d$ vs. time (Fig. 3) can be thus drawn, showing that $\gamma^{\prime}$ coarsening mainly takes place in the first 800 hours, then particle size keeps almost constant.

It is worth pointing out that after 3500 hours ageing at $800^{\circ} \mathrm{C}$ a copious precipitation of Ti-rich needles can be observed (Fig. 4). This acicular phase, namely $\eta$-phase, is more common at grain boundaries and it appears surrounded by $\gamma^{\prime}$-depleted zones. $\gamma^{\prime}$ particles appear aligned, as noticed in [4]. It may be argued that these features could account for a larger scatter band related to $\gamma^{\prime}$ particles size after $3500 \mathrm{~h}$, and for its reduction between 800 and $3500 \mathrm{~h}$.

\subsection{Creep tests}

\subsubsection{Peak-aged samples}

A set of creep test was performed at $800{ }^{\circ} \mathrm{C}$ in the stress range 135-330 MPa on peak-aged samples. Results are shown in Fig. 5. 


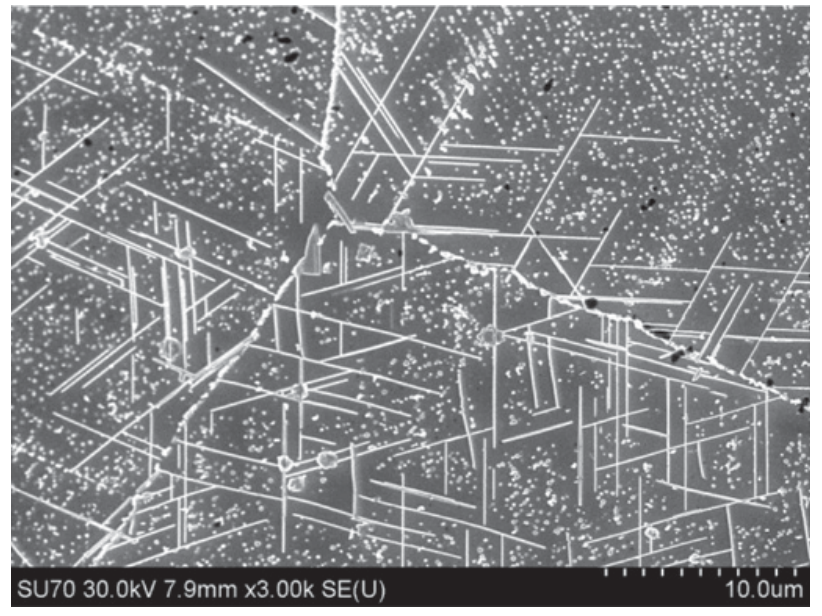

Figure 4. Acicular $\eta$-phase and coarse $\gamma^{\prime}$ particles in a SEM micrograph of Nimonic 263 after 3500 hours ageing at $800^{\circ} \mathrm{C}$.
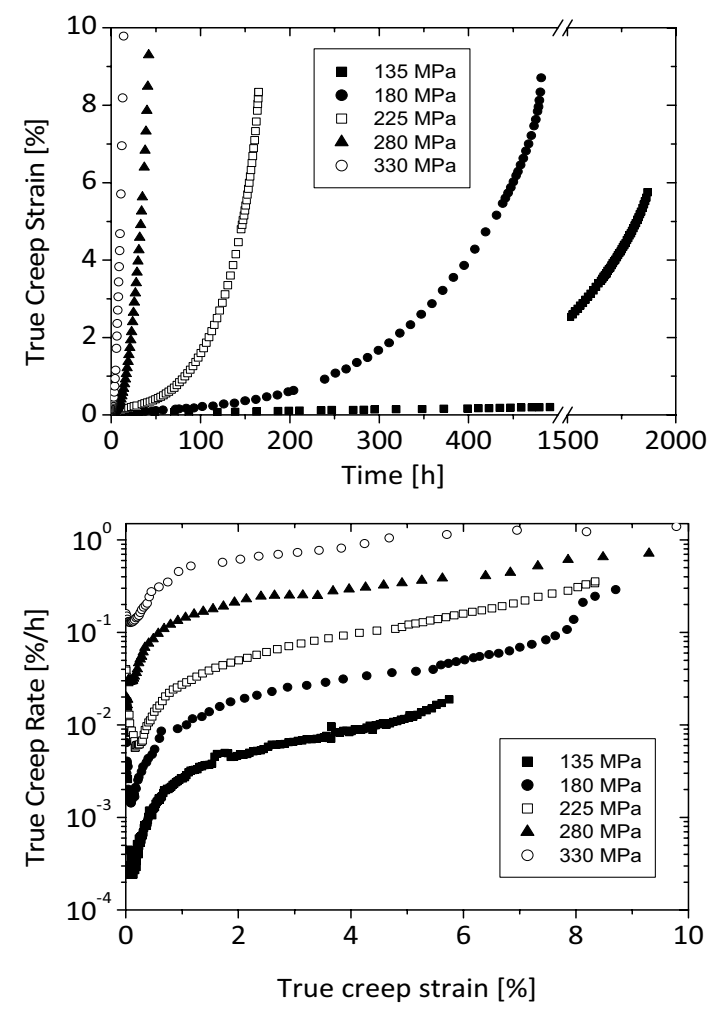

Figure 5. Creep tests at $800^{\circ} \mathrm{C}$ on peak-aged samples: true creep strain vs. time (above) and true creep rate vs. true creep strain (below) plots. Applied stresses are given in the captions inside the graphs.

The general shape of the creep curves is similar in the whole stress range considered, displaying a very short primary stage, followed by a long accelerating stage where strain rate increases almost linearly with strain.

This kind of creep curves can be well described through a system of Kachanov-like (i.e.: in terms of parameters varying from 0 at the beginning of the test and to constant value at the end of the test) coupled differential equations [2].
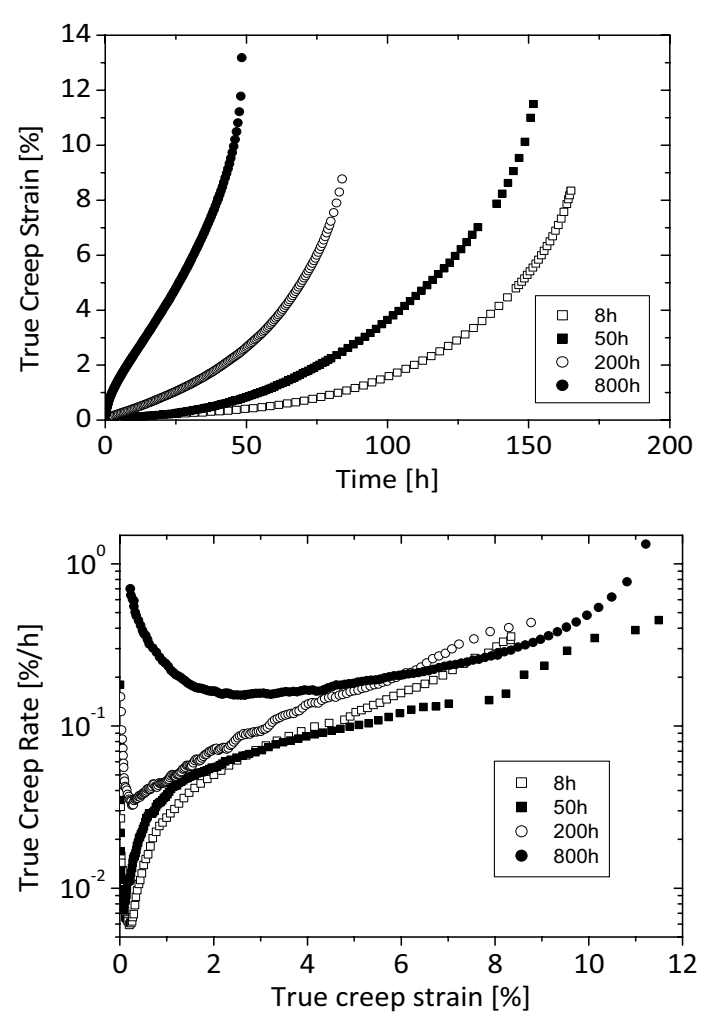

Figure 6. Creep tests at $800^{\circ} \mathrm{C} / 225 \mathrm{MPa}$ on overaged samples: true creep strain vs. time (above) and true creep rate vs. true creep strain (below) plots. Ageing times are given in the captions inside the graphs.

\subsubsection{Overaged samples}

Overaged samples were crept at $800{ }^{\circ} \mathrm{C}$ under applied stress of $225 \mathrm{MPa}$ and $135 \mathrm{MPa}$.

Creep tests at $225 \mathrm{MPa}$ (Fig. 6) on overaged samples show that the shape of creep curves changes with ageing. It is important to notice, though, that overageing not only enhances the minimum creep rate but it also involves a deep change in the creep curve shape. In particular, increasing the overageing, the convex shape of the creep curves in the semi-logarithmic plot creep rate vs creep strain tends to disappear. After 800 hours ageing, the alloy exhibits a large decelerating primary stage and the minimum creep rate is observed at relatively large strains (about $2 \%$ instead of about $0.1 \%$ ).

Creep tests at $135 \mathrm{MPa}$ (Fig. 7) shows that increasing soaking time at $800{ }^{\circ} \mathrm{C}$ reduces creep rupture times and deeply modifies the shape of creep curves. In the peakaged sample creep rate reaches its minimum at a creep strain $<0.1 \%$, than it linearly grows with strain. The $800-$ hours-aged sample shows a similar behaviour for strain lower than $2 \%$, where it seems to undergo a steady state, i.e. creep rate is almost constant. In the 3500-hours-aged, minimum creep rate takes place after about $0.6 \%$, and creep rate increases exponentially with strain.

\subsubsection{Microstructure observations}

Selected creep tests were interrupted in order to provide samples for STEM analyses. Creep tests on peak- and 800 -hours-aged at $225 \mathrm{MPa} / 800^{\circ} \mathrm{C}$ were interrupted at the 

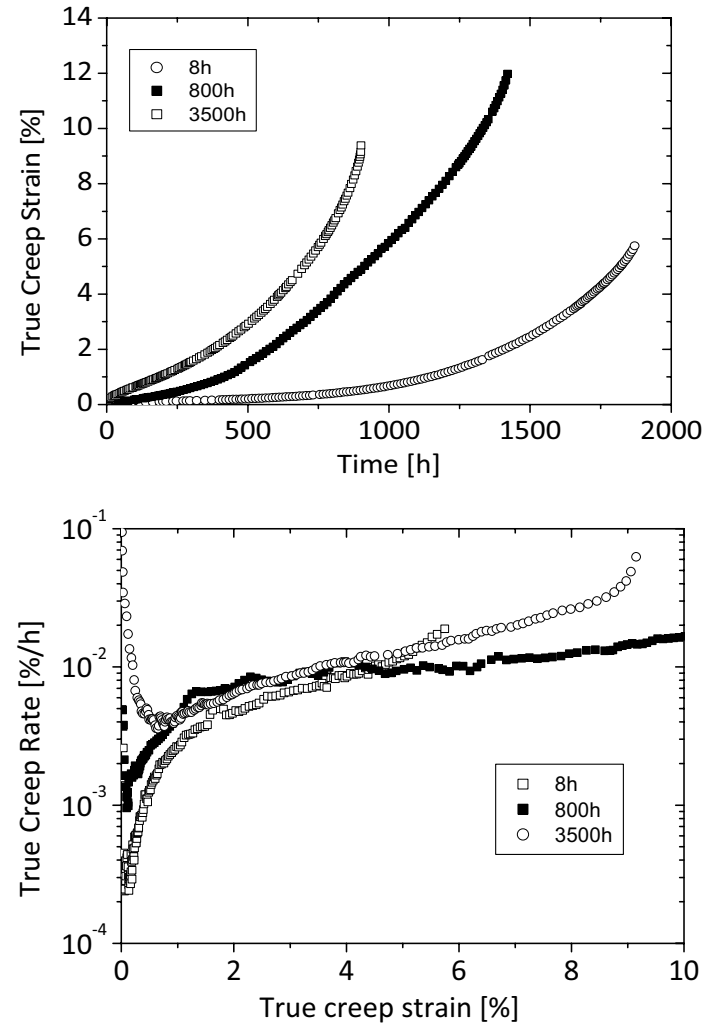

Figure 7. Creep tests at $800^{\circ} \mathrm{C} / 135 \mathrm{MPa}$ on overaged samples: true creep strain vs. time (above) and true creep rate vs. true creep strain (below) plots. Ageing times are given in the captions inside the graphs.

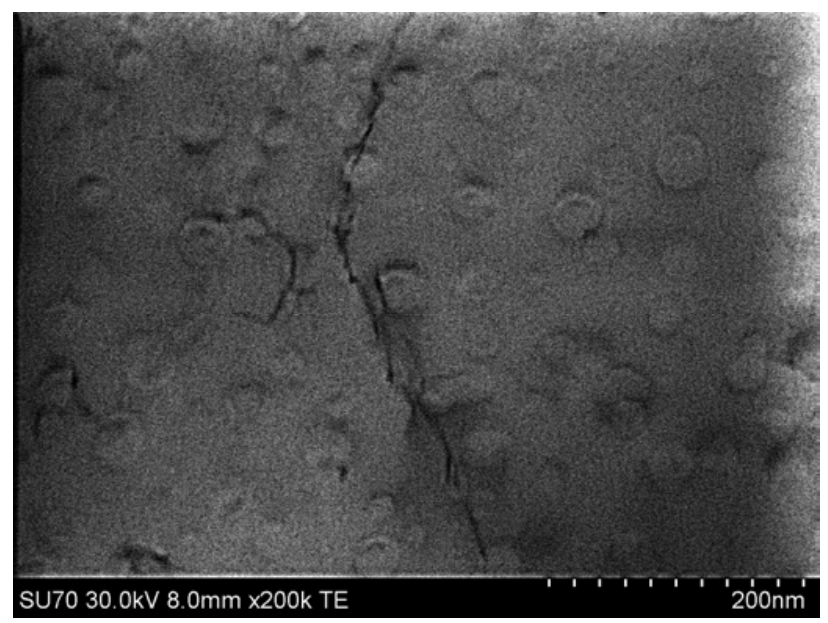

Figure 8. STEM micrograph of a creep sample $\left(800^{\circ} \mathrm{C} / 225 \mathrm{MPa}\right.$, peak aged) after interruption at minimum creep rate (about $0.1 \%$ creep strain).

occurrence of minimum creep rate. Micrographs are shown in Figs. 8 and 9, respectively. The dislocation density looks much higher in the overaged sample, because of the higher creep strain accumulated ( $2 \%$ vs. about $0.1 \%$ ). In both cases, dislocations bow between $\gamma^{\prime}$ particles, while no cutting seems to take place. In the aged sample, some $\gamma^{\prime}$ particles look surrounded by Orowan loops.

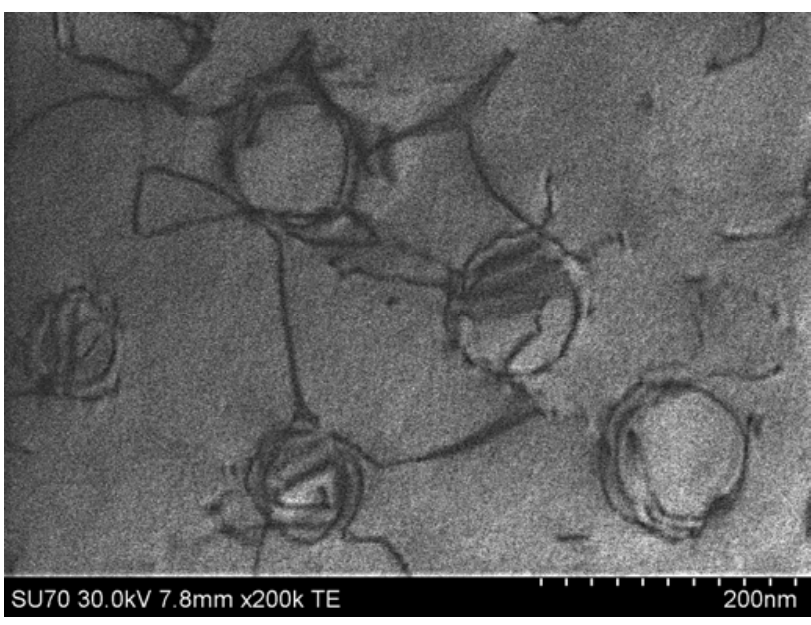

Figure 9. STEM micrograph of a creep sample $\left(800^{\circ} \mathrm{C} / 225 \mathrm{MPa}\right.$, 800 -hours-aged) after interruption at minimum creep rate (about $2 \%$ creep strain).

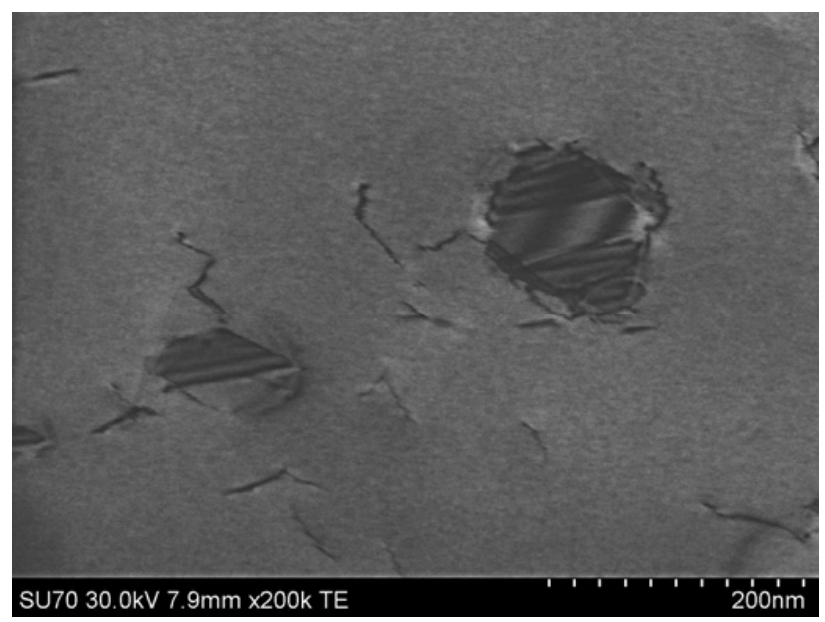

Figure 10. Cut particles in crept sample $\left(135 \mathrm{MPa} / 800^{\circ} \mathrm{C}\right.$, no overageing, time to rupture $1870 \mathrm{~h}$ ).

STEM observations were also performed on samples crept at $135 \mathrm{MPa} / 800^{\circ} \mathrm{C}$. On the peak-aged sample, a large amount of cut particles was detected (Fig. 10). Between particles, dislocation networks were occasionally found (Fig. 11), while $\eta$ phase was hardly detectable. The same comments can be made on the 800-hoursaged sample crept in the same conditions, in which, yet, $\eta$ phase can more easily be noticed. This latter aspect is more apparent with increasing overageing: the sample crept after 3500 hours ageing shows obvious evidence of thick platelets of $\eta$ phase (Fig. 12), as already pointed out (Fig. 4), and volume fraction of $\gamma^{\prime}$ phase appears reduced, even though no quantitative assessment of this remark was performed.

\section{Discussion}

The effect of ageing at $800{ }^{\circ} \mathrm{C}$ on the microstructure of Nimonic 263 alloy is mainly related to the evolution of $\gamma^{\prime}$ particles. Their size increases in the first 800 hours, 


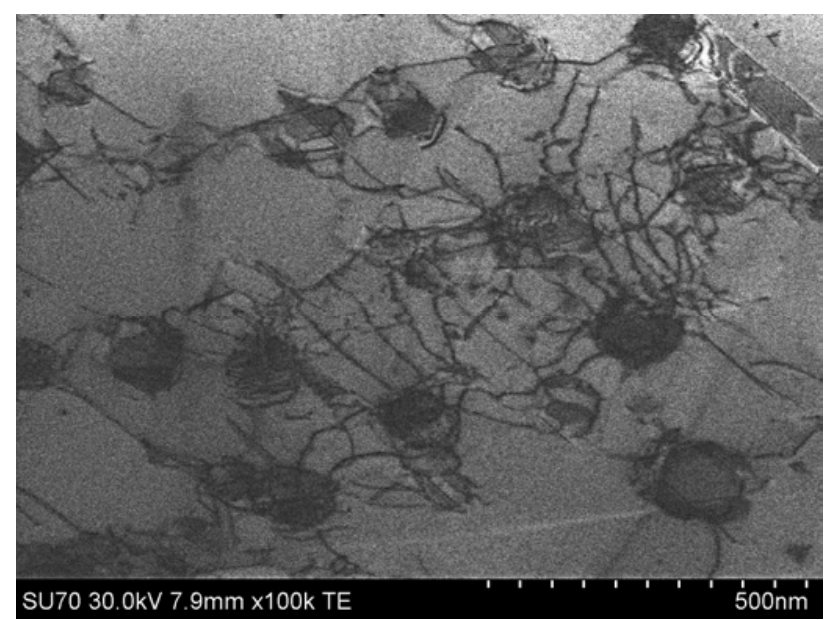

Figure 11. Dislocations network between $\gamma^{\prime}$ particles in crept sample $\left(135 \mathrm{MPa} / 800^{\circ} \mathrm{C}\right.$, no overageing, time to rupture $\left.1870 \mathrm{~h}\right)$.

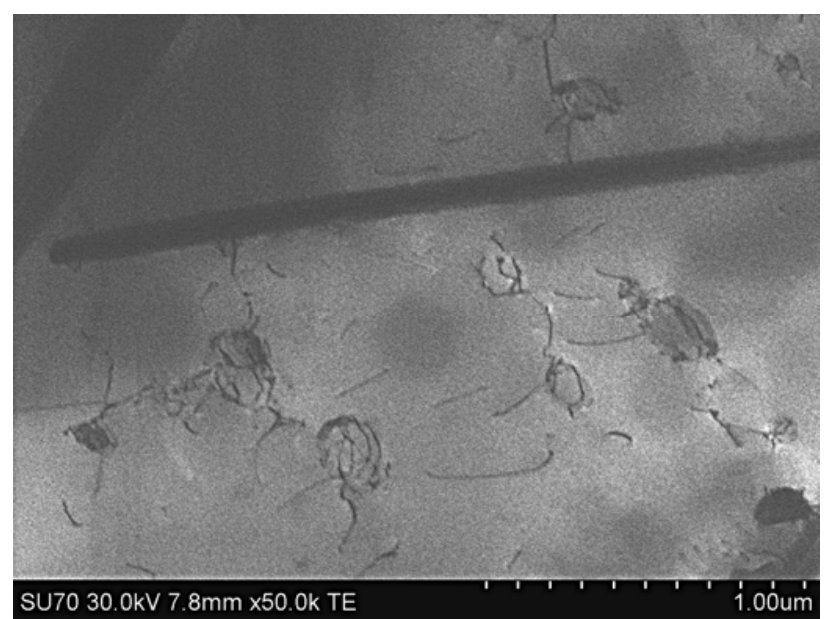

Figure 12. Dislocations pinned at $\gamma^{\prime}$ particles and $\eta$ phase needles in aged and crept sample $\left(135 \mathrm{MPa} / 800^{\circ} \mathrm{C}, 3500 \mathrm{~h}\right.$ ageing, time to rupture $900 \mathrm{~h}$ ).

keeping almost constant with further ageing (Fig. 3). This behaviour can account for the hardness curve depicted in Fig. 1. Figures 10 and 11 show that $\gamma^{\prime}$ particles size in crept samples (time to rupture $1870 \mathrm{~h}$ ) is consistent with the ripening curve (Fig. 3) displayed by aged samples. These values are in turn consistent with reported literature data collected on crept specimens [3], which confirms that coarsening can be assumed independent of applied stress, as observed in another $\gamma^{\prime}$-strengthened nickel base superalloy [7].

Interpolating data with a simple power law, the evolution of $\gamma^{\prime}$-particles size during creep test can be calculated, in order to estimate its influence on creep rate.

Figure 13 shows a plot of true creep rate $\left(800^{\circ} \mathrm{C} / 225 \mathrm{MPa}\right)$ versus $\gamma^{\prime}$ particle size, which suggests that particle size has a strong influence on minimum creep rate (the dependence is roughly exponential, Fig. 14), while the subsequent acceleration cannot be ascribed only to particles coarsening [2].

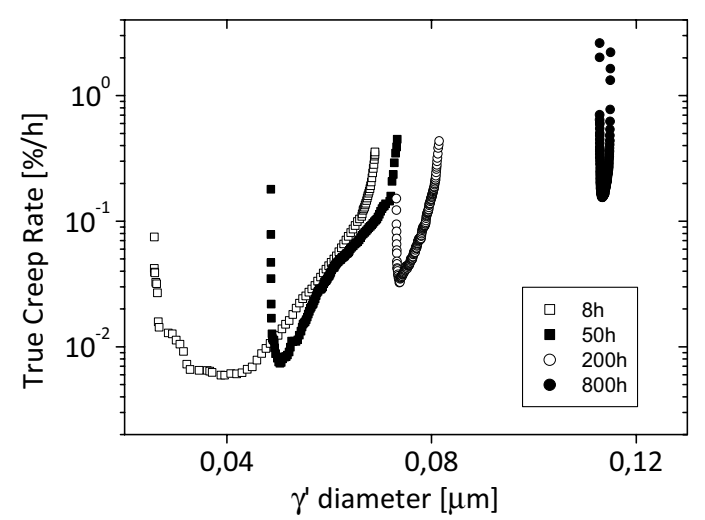

Figure 13. True creep rate $\left(800^{\circ} \mathrm{C} / 225 \mathrm{MPa}\right)$ vs. calculated $\gamma^{\prime}$ particle size in aged samples (ageing times prior to creep tests are given in the captions inside the graph).

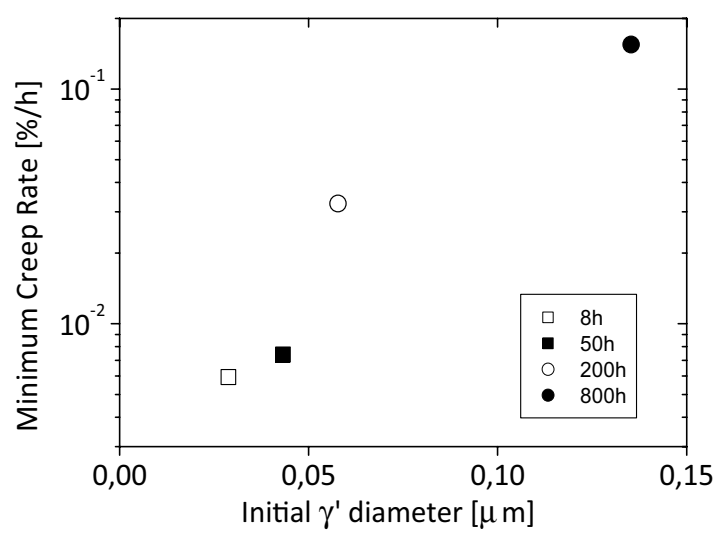

Figure 14. Minimum creep rate $\left(800^{\circ} \mathrm{C} / 225 \mathrm{MPa}\right)$ vs. initial (measured) $\gamma^{\prime}$ particle size in aged samples (ageing times prior to creep tests are given in the captions inside the graph).

It is worth noting that the shape of the accelerating stage varies with ageing. Depending on ageing, indeed, the relationship between creep rate and creep strain changes without suggesting a unique pattern: an exponential relationship holds for $135 \mathrm{MPa} / 3500 \mathrm{~h}$ and for $225 \mathrm{MPa} / 200 \mathrm{~h}$, while a linear relationship holds for the shortest ageing times at 135 and $225 \mathrm{MPa}(8-800 \mathrm{~h}$ and $8-50 \mathrm{~h}$ respectively). Samples aged for $800 \mathrm{~h}$ show a steady state at both stresses, but at $225 \mathrm{MPa}$ the steady state reminds the usual class $\mathrm{M}$ creep behaviour, while at $135 \mathrm{MPa}$ creep under constant rate takes place after an accelerating stage. Note that this latter feature can be seen on the same material when crept at $950{ }^{\circ} \mathrm{C}$ [2], a temperature higher than $\gamma^{\prime}$ solvus temperature where, thus, no $\gamma^{\prime}$ particle strengthening is active.

After prolonged ageing $(3500 \mathrm{~h})$, with an applied stress of $135 \mathrm{MPa}$, the steady state disappears, and creep rate grows exponentially with creep strain. In this sample, $\gamma^{\prime}$ volume fraction looks lower, because of the appearing of the $\eta$ phase needles. This remark is consistent with [4], where it is stated that $\gamma^{\prime}$ is a metastable phase; yet, it is difficult to model how this microstructural evolution can affect the shape of the creep curve.

It is noteworthy that many $\gamma^{\prime}$ particles look cut after creep at $135 \mathrm{MPa} / 800{ }^{\circ} \mathrm{C}$ (Fig. 9), even when their size is considerably large (about $140 \mathrm{~nm}$ ). Micrographs were 
taken after rupture, so it can be argued that dislocation structures may be affected by the stress increase due to necking. In this sample, though, necking is slightly above $10 \%$, which implies that final stress is about $150 \mathrm{MPa}$.

\section{Conclusions}

Creep tests were run on peak aged $\left(8 \mathrm{~h} / 800^{\circ} \mathrm{C}\right)$ and overaged (up to $3500 \mathrm{~h} / 800^{\circ} \mathrm{C}$ ) specimens of Nimonic 263 alloy. Microstructural investigations through SEM/STEM were performed on aged and crept samples. The main results can be summarized:

- Experimental data obtained on specimens aged at $800^{\circ} \mathrm{C}$ indicate that hardness reaches its maximum in 8 hours and sharply decreases to achieve a sort of asymptotical value after 800 hours. The precipitation of $\eta$ phase platelets, observed after prolonged soaking at $800^{\circ} \mathrm{C}$, seems to have little influence on hardness.

- Peak aged samples display similar creep curve, with a small primary stage and a large accelerating tertiary stage. Creep rate increases roughly linearly with creep strain and $\gamma^{\prime}$ particles coarsening does not account for such acceleration.

- Overaged samples show different creep curve shapes, being either the accelerating or the steady the dominant state. Steady state itself, depending on the applied stress, can be preceded by an either decelerating or accelerating stage.

- STEM micrographs suggest that dislocation networks may form and that $\gamma^{\prime}$ particles can be cut even when their size is about $140 \mathrm{~nm}$.

\section{References}

[1] A. Manonukul, F.P.E. Dunne, D. Knowles, Acta Mater., 50, 2917 (2002)

[2] M. Maldini, G. Angella, V. Lupinc, Mater. Sci. Eng. A, 462, 436 (2007)

[3] Y.H. Zhang, D.M. Knowles, Proc. Of the $9^{\text {th }}$ Intl. Conf. On Creep and Fracture of Engg. Materials and Structure

[4] J.C. Zhao, V. Ravikumar, A.M. Beltran, Metall. Mater. Trans. A, 32A, 1271 (2001)

[5] Q. Luo, K. Chi, S. Li, P. Barnard, ASME 2012 Pressure Vessels \& Piping Division Conference, 197 (2012)

[6] R. Higginson, C.M. Sellars, Worked Examples in Quantitative Metallography, (Institute of Materials, London, 2003)

[7] R.A. Stevens, P.E. Flewitt, Mater. Sci. Eng., 37, 237 (1979) 